\title{
ASIAN JOURNAL
}

\section{OF ORGANIC CHEMISTRY}

\section{Accepted Article}

Title: Conjoint use of dibenzosilole and indan-1,3-dione functionalities to prepare an efficient non-fullerene acceptor for solution-processable bulk-heterojunction devices

Authors: Sheshanath V. Bhosale; Hemlata Patil; Akhil Gupta; Ben Alford; Di Ma; Steven H Privér; Ante Bilic; Prashant Sonar

This manuscript has been accepted after peer review and the authors have elected to post their Accepted Article online prior to editing, proofing, and formal publication of the final Version of Record (VoR). This work is currently citable by using the Digital Object Identifier (DOI) given below. The VoR will be published online in Early View as soon as possible and may be different to this Accepted Article as a result of editing. Readers should obtain the VoR from the journal website shown below when it is published to ensure accuracy of information. The authors are responsible for the content of this Accepted Article.

To be cited as: Asian J. Org. Chem. 10.1002/ajoc.201500207

Link to VoR: http://dx.doi.org/10.1002/ajoc.201500207

Supported by:

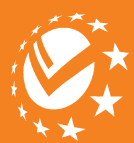

ChemPubsoc

Europe 


\title{
Conjoint use of dibenzosilole and indan-1,3-dione functionalities to prepare an efficient non-fullerene acceptor for solution-processable bulk- heterojunction devices
}

\author{
Hemlata Patil,${ }^{[a]}$ Akhil Gupta, ${ }^{[a]}$ Ben Alford,${ }^{[\mathrm{a}]}$ Di Ma,${ }^{[\mathrm{b}]}$ Steven H. Privér ${ }^{[\mathrm{a}]}$ Ante Bilic ${ }^{[\mathrm{c}]}$ Prashant Sonar, ${ }^{[\mathrm{d}]}$ and \\ Sheshanath V. Bhosale ${ }^{\text {[a] }}$
}

\begin{abstract}
A novel, solution-processable non-fullerene electron acceptor, 2,2'-(( $\quad 25,5$-dioctyl-5H-dibenzo[ $b, d]$ silole-3,7diyl)bis(thiophene-5,2-diyl))bis(methanylylidene))bis( $1 H$-indene-

1,3(2H)-dione) (coded as N5) comprised of dibenzosilole and 1,3indanedione building blocks was designed, synthesized and fully characterized. N5 exhibited excellent solubility in various organic solvents, showed high thermal stability and acquired energy levels matching with those of archetypal donor poly(3-hexylthiophene). Solution-processable bulk-heterojunction devices afforded promising power conversion efficiency $(2.76 \%)$ when $\mathbf{N 5}$ was used as a nonfullerene electron acceptor along with the conventional donor polymer poly(3-hexylthiophene). As per our knowledge, the material reported herein is the first example in the literature where synchronous use of such building blocks is demonstrated to design an efficient nonfullerene acceptor.
\end{abstract}

\section{Introduction}

There is a significant attention towards the design and development of new organic semiconductors for organic photovoltaic (OPV) devices. OPV devices are divided into two major types in which one is bilayer and the other is bulk heterojunction (BHJ) device type. In the bilayer devices, two distinct electron donor and acceptor layers are deposited on top of each other between the electrodes whereas in BHJ devices, an active photon absorbing layer is a bi-continuous interpenetrating network of an electron donor and an electron

[a] H. Patil, Dr. A. Gupta, Dr. B. Alford, Dr. S. H. Privér, Dr. S. V. Bhosale

School of Applied Sciences

RMIT University

GPO Box 2476, Melbourne Victoria 3001 Australia

E-mail: sheshanath.bhosale@rmit.edu.au; akhilgk15@gmail.com

[b] Dr. D. Ma

College of Material Science and Engineering,

Beijing University of Chemical Technology,

Beijing 100029 China

[c] Dr. A. Bilic

CSIRO Manufacturing, Virtual Nanoscience Lab

Parkville Victoria 3052 Australia

[d] Dr. P. Sonar

School of Chemistry, Physics and Mechanical Engineering,

Queensland University of Technology, GPO Box 2434, Brisbane

QLD 4001 Australia

Supporting information for this article is given via a link at the end of the document. acceptor. ${ }^{[1]}$ The most examined and widely accepted BHJ system is a blend of donor polymer poly(3-hexylthiophene) (P3HT) and solubilised fullerene derivative [6,6]-phenyl $\mathrm{C}_{61}$ butyric acid methyl ester $\left(\mathrm{PC}_{61} \mathrm{BM}\right)$ as an acceptor. From the materials perspective, considerable research has been done on the design and development of polymeric as well as small molecular donors, ${ }^{[2-6]}$ but for electron acceptors, there is limited number of materials reported in the literature. Power conversion efficiencies (PCEs) stemmed from the development of donors and fullerene acceptors have surpassed the $10 \%$ mark, ${ }^{[7]}$ however, linger around 3\% from the development of non-fullerene acceptors, ${ }^{[8-22]}$ albeit reports from S. Holliday et al., J. Zhao et al. and Y. Lin et al. displayed over $4 \%$ and $6 \%$ with the use of P3HT and nonP3HT donors. ${ }^{[23-26]}$ Although the PCEs with the use of non-fullerene acceptors are moving upwards and various research groups are trying to achieve big numbers, it is vital to mention that in order to make these acceptors viable for practical applications one must consider their foremost suitability with easily synthesizable and commercially available donors such as P3HT. This requirement dares a great challenge for an organic chemist to investigate new building blocks which can potentially be used for the design and development of nonfullerene acceptors. In this paper, we describe an innovative small molecular electron acceptor and demonstrate that union of carefully selected building blocks can inevitably be used to generate promising non-fullerene electron accepting chromophores.

With regard to conventional photoactive acceptors, $\mathrm{PC}_{61} \mathrm{BM}$ or $\mathrm{PC}_{71} \mathrm{BM}$ are the acceptors of choice mainly due to their inherent properties such as large electron affinity, high electron mobility, good solubility, ability to form a favourable nanoscale network with donor materials and isotropy of charge transport. ${ }^{[27]}$ However, these highperforming and versatile acceptors are afflicted with a number of shortcomings such as electronic tuning via structural modification, weak absorption in the visible spectrum and large electron affinity that can outcome in low open-circuit voltage $\left(V_{\text {oc }}\right)$ of BHJ devices. ${ }^{[28]}$ To understand and solve these problems, electron acceptor materials should be designed by considering crucial factors such as strong and broad absorption, adequate solubility and appropriate energy levels. Recently, non-fullerene electron acceptors have been explored and reviews by P. Sonar et al. and Y. Lin et al. are the key examples of their development. ${ }^{[29,30]}$

Even though the advancement of non-fullerene acceptors is noteworthy, incentives remain to develop materials which will not only fill-in the gap for fullerenes but will also exert imperative characteristics such as solubility and matching energy levels with donors. One strategy to design such materials is the conjoint use of donor and acceptor functionalities which can be arranged in a 
meaningful manner to generate an elongated conjugated system. Inspired by the recent use of versatile donor and acceptor building blocks, ${ }^{[9,13,14,16,23,31,32]}$ functionalities such as dibenzosilole (DBS) and 1,3-indanedione (IDO) were identified as potentially suitable electrondonor and -deficient templates in order to generate a target chromophore that can acquire elongated conjugation, thermal and photochemical stability, and can excel in solubility. Herein we report the design, synthesis and characterization of the optoelectronic and photovoltaic properties of a novel small molecular non-fullerene electron acceptor, 2,2'-(( $\quad 5,5$-dioctyl-5H-dibenzo[ $b, d]$ silole-3,7diyl)bis(thiophene-5,2-diyl))bis(methanylylidene) $)$ bis( $1 H$-indene-

$1,3(2 H)$-dione) (coded as N5; Figure 1), based on DBS and IDO building blocks. Replacement of carbon with silole moiety, i.e. from fluorene to DBS, is an interesting chemical modification that has been studied with keenness as silole derivatives can also exhibit electrontransporting properties. ${ }^{[33]}$ DBS unit in particular is a kind of silolecontaining fused ring which has been implemented for DBS-based polymers, and such polymers have shown promising performance in organic electronic devices such as light-emitting diodes, ${ }^{[34]}$ field-effect transistors, ${ }^{[35]}$ and solar cells. ${ }^{[36]}$ However, to our knowledge, there are very limited reports on the DBS-based materials as non-fullerene acceptors. ${ }^{[9]}$ This state of affairs inspired us and provided an opportunity to investigate the use of DBS-based chromophores, and we were able to envision $\mathbf{N 5}$.

By designing and developing $\mathbf{N 5}$ we were able to demonstrate that N5, when blended with P3HT in solution-processable BHJ solar cells, can deliver promising PCE that approaches $~ 3 \%$, and that the BHJ devices based on the combination of DBS-IDO building blocks show better performance than the devices based on the combination of fluorene-IDO blocks. To our knowledge, there are no reports on the conjoint use of DBS and IDO building blocks to generate a nonfullerene electron acceptor for solution-processable BHJ devices. The present work is a continuation of our efforts on the design and development of small molecular chromophores for organic electronic devices. $^{[37-40]}$

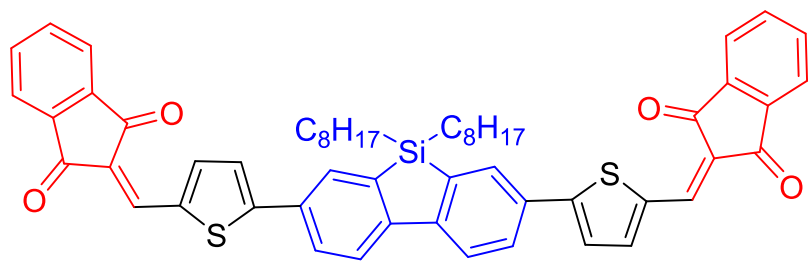

\section{N5}

Figure 1. Molecular structure of the newly designed, synthesized and characterized non-fullerene electron acceptor N5.

\section{Result and Discussion}

\section{Synthesis}

Compound N5 was successfully synthesized via Suzuki coupling of 9,9-dioctyl-9H-9-silafluorene-2,7-bis(boronic acid pinacol ester) with 5-bromothiophene-2-aldehyde followed by a Knoevenagel condensation reaction with 2,3-dihydro- $1 H$-indene-1,3-dione (see scheme 1). N5 was obtained as red crystalline material in yield of $72 \%$ and the synthetic route of $\mathbf{N 5}$ was simple, facile and viable to generate multi-gram quantities (> 5g). N5 was fully characterized by high resolution mass spectrometry, ${ }^{1} \mathrm{H}$ and ${ }^{13} \mathrm{C}$ NMR spectroscopy, and $\mathrm{X}$ ray crystallography. The molecular structure of N5, obtained as a dichloromethane solvate, is shown in Figure 2 (see also Fig. S1 and Table S1 in the Supporting Information (SI). In general, the metrical parameters in N5 are comparable to those observed in the closely related structure in which the silicon atom was replaced by carbon. ${ }^{[32]}$ As expected, the $\mathrm{Si}-\mathrm{C}$ bonds in N5 are ca. 1.2 times longer than the corresponding $\mathrm{C}-\mathrm{C}$ in the literate analogue and the geometry about the silicon atom is distorted tetrahedral. Notably, the $\mathrm{C} 1-\mathrm{Si} 1-\mathrm{C} 21$ angle is significantly smaller $\left[91.00(11)^{\circ}\right]$ than the corresponding angle in Canalogue $\left[99.8(2)^{\circ}\right]$, presumably to accommodate the larger silicon atom, while the $\mathrm{C} 1-\mathrm{Si} 1-\mathrm{C} 41$ angle is significantly larger $\left[117.25(12)^{\circ}\right.$ vs $\left.110.5(2)^{\circ}\right]$. In the solid state, stacking of the indan-1,3-dione moieties to neighbouring molecules takes place, the intermolecular separation being about $3.4 \AA$; similar behaviour was also observed in the molecular structure of $\mathrm{C}$-analogue.<smiles>CC1(C)OB(c2ccc3c(c2)[Si]([13CH2])([13CH2])c2cc(B4OC(C)(C)C(C)(C)O4)ccc2-3)OC1(C)C</smiles><smiles>CC(C)CC(=O)c1ccc(Br)s1</smiles><smiles>[13CH2][Si]1([13CH2])c2cc(-c3ccc(C=O)s3)ccc2-c2ccc(-c3ccc(C=O)s3)cc21</smiles><smiles>O=C1CC(=O)c2ccccc21</smiles>

N5

Scheme 1. Synthetic route to N5. Reagents and conditions: a) $\mathrm{Pd}\left(\mathrm{PPh}_{3}\right)_{4}$, dimethoxyethane, $2 \mathrm{M} \mathrm{Na}_{2} \mathrm{CO}_{3}, \mathrm{~N}_{2}, \mathrm{RT}, 12 \mathrm{~h}, 73 \%$; b) $t$ - $\mathrm{BuOH} /$ piperidine, reflux, $12 \mathrm{~h}$, $72 \%$.

N5 was found to be highly soluble in a variety of common organic solvents, such as dichlorobenzene, toluene and chloroform (for instance, $>20 \mathrm{mg} / \mathrm{mL}$ in $o$-dichlorobenzene). High solubility is a vital feature required for the fabrication of small molecular organic semiconductors, and $\mathbf{N 5}$ being adequate soluble fulfils this criterion. Thermogravimetric analysis (TGA) and differential scanning calorimetry (DSC) analyses revealed that $\mathbf{N 5}$ exhibits excellent thermal stability (decomposition temperature $\sim 393{ }^{\circ} \mathrm{C}$ from DSC analysis), a finding that gives assistance to the fact that P3HT:N5 devices can be thermally annealed (for TGA and DSC curves, please see Figure S2, SI). 
a)

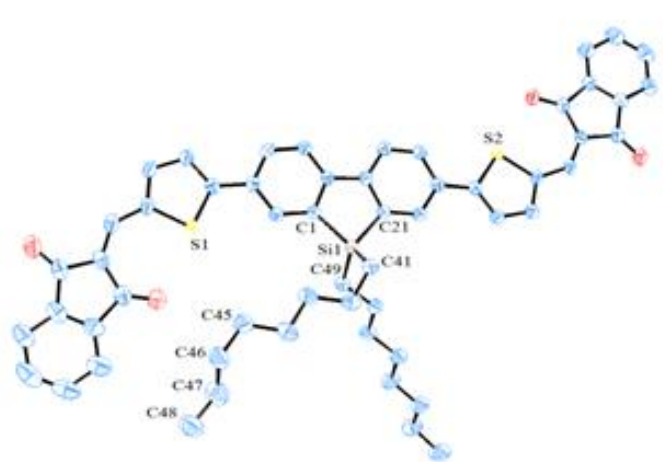

b)

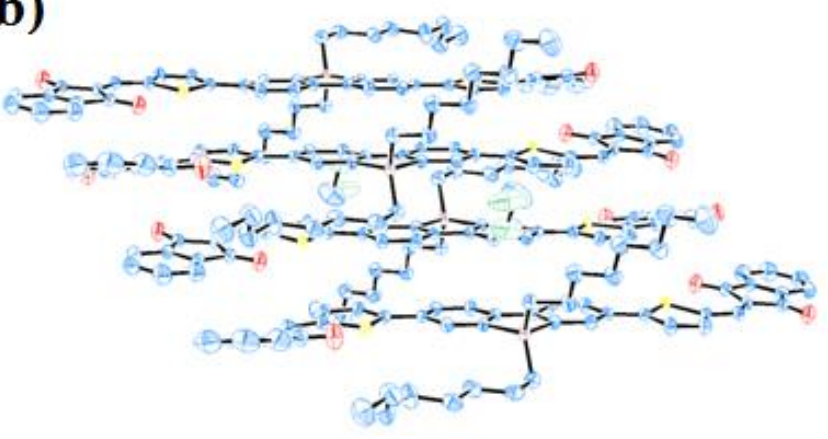

Figure 2. (a) Molecular structure of $\mathrm{C}_{56} \mathrm{H}_{54} \mathrm{O}_{2} \mathrm{~S}_{2} \mathrm{Si} \cdot \mathrm{CH}_{2} \mathrm{Cl}_{2}\left(\mathbf{N 5} \cdot \mathrm{CH}_{2} \mathrm{Cl}_{2}\right)$. Ellipsoids show $50 \%$ probability levels. Hydrogen atoms and disordered dichloromethane of solvation have been omitted for clarity. The alkyl chain at C45-C48 was disordered over two positions and only the major orientation (0.8342) is shown. (b) Molecular packing in the crystal of N5. The CCDC number obtained for N5 is CCDC1048201.

The ultraviolet-visible (UV-Vis) spectra of N5 measured in chloroform solution and in thin solid films are shown in Figure 3. In solution, N5 exhibited the longest wavelength absorption maximum $\left(\lambda_{\max }\right)$ at $492 \mathrm{~nm}$ with an absorbance onset at around $560 \mathrm{~nm}$. Film spectra were measured on cleaned glass substrates. Generally, for a given compound, the thin film absorption spectrum will exhibit a bathochromic shift as compared to its solution spectrum. In this study, N5 also exhibited a bathochromic shift in its film spectrum, and this observation is in good agreement with the literature reported materials. ${ }^{[37,40]}$ The $\lambda_{\max }$ was red-shifted in the pristine state and the spectrum was broadened over the visible range. Latter was also true for the blend absorption of P3HT:N5.

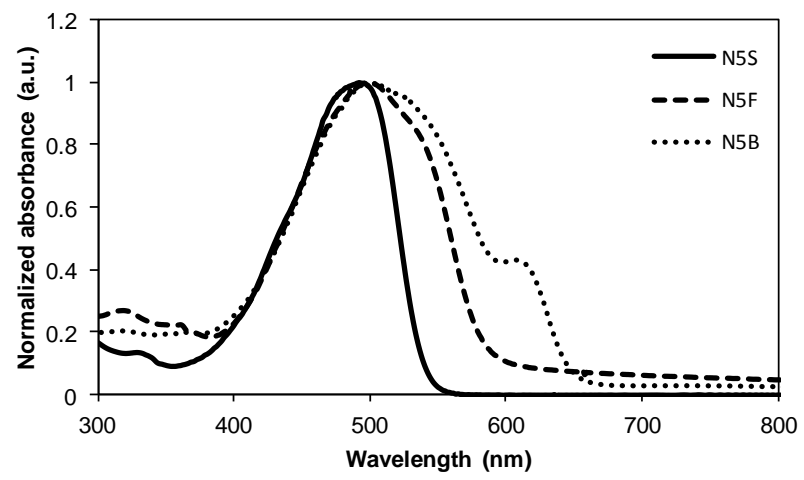

Figure 3. UV-Vis absorption spectra of $\mathbf{N 5}$ in chloroform solution (N5 S; solid curve), as-casted pristine film (N5 F; dashed curve) and 1:1 blend with P3HT (N5 B; dotted curve).
The fluorescence quenching ability of $\mathbf{N 5}$ blended with P3HT was investigated to observe its potential utility as an electron acceptor for photovoltaic application. The fluorescence (FL) quenching measurement can provide valuable insight about the ability of donoracceptor interface to dissociate excitons. The blend film of P3HT:N5 $(1: 1 \mathrm{w} / \mathrm{w})$ revealed quenching of FL (Figure S3, SI), a finding that is in agreement with the literature reported non-fullerene acceptors. ${ }^{[14]}$

Density functional theory (DFT) calculations using the Gaussian 09 suite of programs ${ }^{[41]}$ and B3LYP/6-311+G(d,p)//B3LYP/6-31G(d) level of theory indicated that orbital densities are evenly distributed over the whole molecular backbone, an observation that is quite customary with small molecular non-fullerene acceptors (see Figure 4) ${ }^{[14,32]}$ Based on the DFT calculations it was further realized that the torsional angle between the two wings (from thiophene to the end) and the central DBS block was as large as $23.7^{\circ}$. These two wings were mutually parallel, as shown in Figure S4; SI, giving the molecule a non-planar structure overall, an observation matching with the crystallographic data. S. Holliday et al. ${ }^{[23]}$ have shown that structures with a hint of non-planarity can perform better than their planar counterparts. As such, the highest occupied molecular orbital (HOMO) and lowest unoccupied molecular orbital (LUMO) energy levels were estimated using a combination of photoelectron spectroscopy in air (PESA) and UV-Vis spectroscopy on thin films. The HOMO energy level was estimated as $-5.71 \mathrm{eV}$ and the LUMO energy level was calculated using the onset of UV-Vis absorbance $(600 \mathrm{~nm})$ of N5. The observed HOMO value of N5 was quite lower, mainly due to the presence of two electron withdrawing IDO groups at the terminals. The LUMO energy level of $\mathbf{N 5}$ is around $-3.64 \mathrm{eV}$, which indicates its apparent suitability to be an electron acceptor in conjunction with P3HT donor (For energy level diagram and PESA curve please see Figure 5 and Figure S5, SI, respectively). The LUMO level of N5 is higher than the literature reported fluorene analogue $(-3.75 \mathrm{eV}),{ }^{[32]}$ which is beneficial for achieving high $V_{\mathrm{oc}}$.

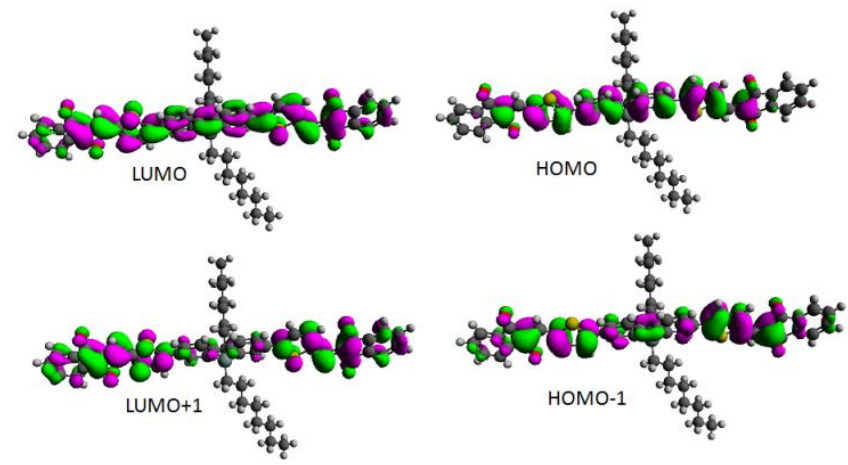

Figure 4. Orbital density distribution for the HOMOs and LUMOs of N5. DFT calculations were performed using the Gaussian 09 suite of programs and B3LYP/6 $311+\mathrm{G}(\mathrm{d}, \mathrm{p}) / / \mathrm{B} 3 \mathrm{LYP} / 6-31 \mathrm{G}(\mathrm{d})$ level of theory. 

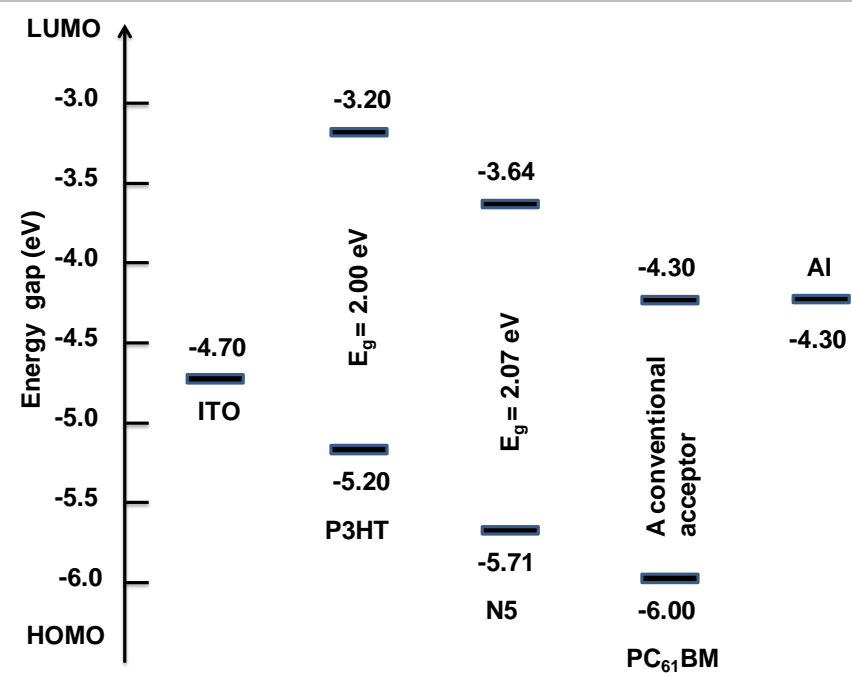

Figure 5. Energy level diagram depicting the band gaps of N5 in comparison with $\mathrm{P} 3 \mathrm{HT}$ and a conventional $\mathrm{PC}_{61} \mathrm{BM}$ acceptor.

As $\mathbf{N 5}$ displayed promising optical and electrochemical properties, we decided to fabricate solution-processable BHJ devices using $\mathbf{N 5}$ as an acceptor. The BHJ devices were fabricated using the classical donor polymer $\mathrm{P} 3 \mathrm{HT}$ as it has the potential to be generated via low cost and high throughput methods. ${ }^{[42]}$ For comparison, we also fabricated the P3HT:PC ${ }_{61} \mathrm{BM}$ devices under similar conditions. Simple device architecture was chosen due to stability, reproducibility, ease of fabrication and solution processability. The BHJ device architecture used was ITO/PEDOT:PSS (38 nm)/active layer $(58 \mathrm{~nm}) / \mathrm{Ca}(20$ $\mathrm{nm}) / \mathrm{Al}(100 \mathrm{~nm})$ where the active layer was a 1:1 blend of P3HT:N5, spin-casted from $o$-dichlorobenzene on top of the PEDOT: PSS surface Y. Kim et al. ${ }^{[31]}$ Y. Lin et al. ${ }^{[15]}$ and H. Patil et al. ${ }^{[10]}$ have shown that thermal annealing of devices incorporating small molecular nonfullerene acceptors and use of high boiling solvents, such as $o$ dichlorobenzene, during the fabrication of photovoltaic devices is beneficial for higher current density and optimal cell performance. Keeping such conditions in mind, we used $o$-dichlorobenzene as the processing solvent and annealed our blend films at $110{ }^{\circ} \mathrm{C}$ for $5 \mathrm{~min}$. The preliminary BHJ devices based on the blends of P3HT:N5 afforded promising performance and the photovoltaic cell parameters, $V_{\text {oc }}$, short circuit current density $\left(J_{\text {sc }}\right)$, fill factor $(\mathrm{FF})$ and PCE, reached $0.78 \mathrm{~V}, 7.61 \mathrm{~mA} \mathrm{~cm}{ }^{-2}, 0.46$ and $2.76 \%$, respectively. By contrast, the maximum PCE, $V_{\text {oc }}$ and $J_{\mathrm{sc}}$ reached $2.85 \%, 0.61 \mathrm{~V}$ and $7.91 \mathrm{~mA} \mathrm{~cm}$, respectively, for a device based on $\mathrm{P} 3 \mathrm{HT}: \mathrm{PC}_{61} \mathrm{BM}$ when fabricated under similar conditions, thus suggesting the reliability of our device strategy (Figure S6, SI). The N5 fabricated devices (a total of six devices were made) yielded high $V_{\text {oc }}$, a finding that is in agreement with the measured optical band gap between the LUMO of N5 and the HOMO of P3HT. The obtained $V_{\text {oc }}$ was higher than the literature reported fluorene-IDO based devices, ${ }^{[32]}$ hence, confirms the better positioning of HOMO and LUMO of N5 and promotes the use of DBSIDO combination.

It was also observed that annealing of active films at higher temperatures, for example at $120{ }^{\circ} \mathrm{C}$, resulted in minor cracks to film surfaces and poor photovoltaic performance. Former was particularly true when low boiling solvent, such as chloroform, was used, hence justifying the literature observation of using high boiling solvent. ${ }^{[14,31]}$ The use of high-boiling solvent is further preferable from a processing point of view. It is also notable that all the devices afforded PCE > $2.5 \%$ and the reported results are for the best photovoltaic device. It is worth mentioning that even though the PCEs with the use of nonfullerene acceptors are surging, ${ }^{[23-26]}$ the DBS-based acceptors still straggle in design, development and efficiency. ${ }^{[30]}$ Having said that, the design and development of N5 is novel and provided PCE among the top values reported in the literature for DBS-based chromophores, ${ }^{[28,29]}$ thus advocating the conjoint use of electron donating and accepting building blocks, of which DBS and IDO are favourable examples, in order to generate a highly conjugated chromophore as an interesting structural concept for the design and development of non-fullerene acceptors. Representative current-voltage $(J-V)$ curve is shown in the Figure 6.

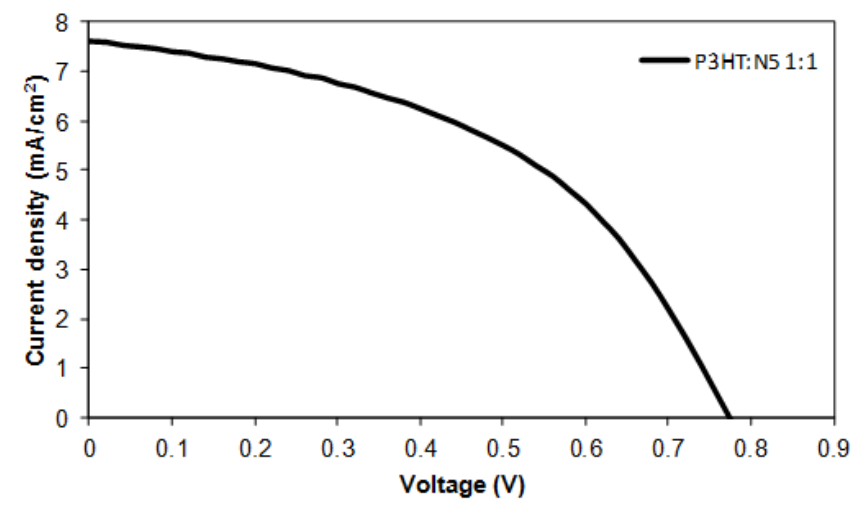

Figure 6. Current-voltage curve for the best device based on N5 and P3HT blend (1:1 w/w) under simulated sunlight (AM1.5, $1000 \mathrm{~W} \mathrm{~m}^{-2}$ ). Device structure is: ITO/PEDOT:PSS (38 nm)/active layer $(58 \mathrm{~nm}) / \mathrm{Ca}(20 \mathrm{~nm}) / \mathrm{Al}(100 \mathrm{~nm})$.

Incident-photon-to-current conversion efficiency (IPCE) measurement of the blend film with a donor-acceptor weight ratio of 1:1 is shown in Figure S7, SI. Broad spectrum IPCE over the whole visible region indicated that both donor and acceptor components in the BHJ blend have participated for drawing out the IPCE and $J_{\text {sc }}$. The IPCE value for P3HT:N5 device reached a maximum of approximately $25 \%$ at around $550 \mathrm{~nm}$. We also observed that the IPCE of $\mathbf{N 5}$ active device was slightly red-shifted than its absorption spectrum. This slight bathochromic shift can be attributed to either uneven surface morphology or film thickness at an incident point on the blend surface. Such divergent variations in solution-processable thin film devices are also common in similar types of photochemical cells where multiple conducting surfaces are coated on top of each other. ${ }^{[43]}$ However, in the limelight of this broad IPCE, sound optical profile and appropriately positioned energy levels it is anticipated that $\mathbf{N 5}$ can also be a suitable acceptor for other electron donating low-band gap conjugated polymers and small molecular solids.

Microstructure analysis of the P3HT:N5 blend surface deposited on ITO coated glass was examined by conventional atomic force microscopy (AFM) technique in tapping mode. The actual surface morphology of the blend film of P3HT:N5 $(1: 1 \mathrm{w} / \mathrm{w})$ is shown in Figure 7. The blend appears to have crystalline grains with a rootmean-square (RMS) roughness of $1.2 \mathrm{~nm}$. Though the crystalline grains may be a result of P3HT self-organization, a finding that is beneficial to ordered structure formation and charge transport in thin film, ${ }^{[44]}$ an interpenetrating network of donor-acceptor components was observed which can be beneficial to exciton dissociation, charge carriers transport and can result in enhanced efficiency of the 
photovoltaic devices. This network of the conventional donor (P3HT) and acceptor $\left(\mathrm{PC}_{61} \mathrm{BM}\right)$ components was found to be superior than the reported N5, hence the device exterted better current and PCE (for the AFM image of P3HT: $\mathrm{PC}_{61} \mathrm{BM}$ device please see Figure $\mathrm{S} 8$ in SI). Although the efficiency of our best performing device is among the top values reported in literature for the DBS-based non-fullerene chromophores, we achieved lower values of FF. The lower value of FF can be attributed to the imbalance of hole and electron mobilities of donor and acceptor components used in the blend. The hole and electron mobilities were measured using transistor devices and the values for electron and hole were measured in the range of $10^{-6}$ and $10^{-}$ ${ }^{4}$ respectively. Higher hole mobility indicated that the presence of N5 does not disrupt the hole-rich P3HT, an observation consistent with blend film absorption (strong shoulder peak over $600 \mathrm{~nm}$ ).

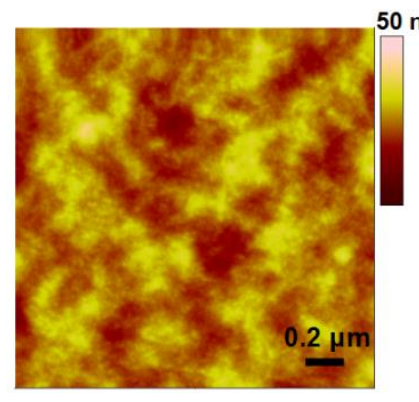

\section{$50 \mathrm{~nm}$}

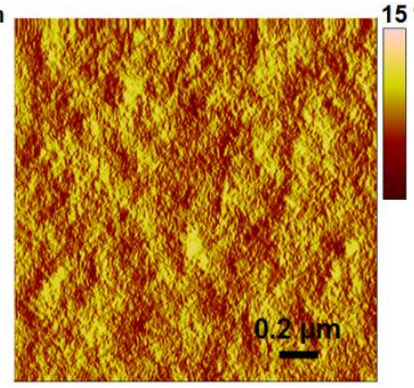

Figure 7. AFM image for the blend film of P3HT:N5 annealed at $110^{\circ} \mathrm{C}$ for $5 \min (10$ mg P3HT, 10 mg N5 in 1 mL $o$-dichlorobenzene @ $2500 \mathrm{rpm}$ ).

Despite the fact that research for non-fullerene electron acceptors is on surge, this work clearly demonstrates the possibility of achieving promising power conversion efficiency in terms of design, chemistry and efficacy. Not only it demonstrates that careful selection of versatile building blocks and their union is vital for the development of new non-fullerene acceptors, but also advocates the advantages of simple and smart chemistry that is achievable by rational design.

\section{Conclusions}

In summary, a novel, solution-processable highly conjugated chromophore, N5, was designed and developed as an electron acceptor for organic solar cells. It exerted excellent thermal stability, strong and broad absorption and appropriate energy levels matching with those of the classical donor polymer P3HT. The blend film of P3HT:N5 exhibited good nanoscale interpenetrating network, broad spectrum IPCE over the visible range and PCE as high as $2.76 \%$, which is among the highest values reported so far for the solution-processable BHJ devices using DBS-based non-fullerene acceptors. Lastly, the P3HT:N5 device is well-suited to the simple device architecture with no special treatment, which offers advantages over complex device strategies. Evidently, this work demonstrates that small molecule acceptors, such as $\mathbf{N 5}$, with promising optoelectronic properties have a bright prospect to be at the leading edge of non-fullerene acceptor research and bridges the gap between the research fields of donor and acceptor semiconducting materials.

\section{Experimental Section}

\section{Chemistry}

Materials: All the reagents and chemicals used, unless otherwise specified, were purchased from Sigma-Aldrich Co. The solvents used for reactions were obtained from Merck Speciality Chemicals (Sydney, Australia) and were used as such. 9,9-Dioctyl-9H-9-silafluorene-2,7bis(boronic acid pinacol ester) was purchased from Luminescence Technology Corporation, Taiwan and was used as such.

Instruments and characterization: Unless otherwise specified, all the NMR spectra were recorded using a Bruker Avance III $300 \mathrm{MHz}$ spectrometer where the residual solvent peaks from the deuterated solvents $\left(\mathrm{CDCl}_{3}{ }^{1} \mathrm{H} \delta=7.26 \mathrm{ppm},{ }^{13} \mathrm{C} \delta=77.0 \mathrm{ppm}\right)$ were used as the reference. Chemical shifts $(\delta)$ are measured in parts per million (ppm). Thin Layer Chromatography (TLC) was performed using $0.25 \mathrm{~mm}$ thick plates precoated with Merck Kieselgel 60 F254 silica gel, and visualised using ultraviolet (UV) light (254 nm and $365 \mathrm{~nm})$. Melting points were recorded on a Stuart SMP10 melting point apparatus and are uncorrected. High resolution mass spectra (HRMS) spectra were recorded on Thermo Scientific Q Exactive FTMS, employing ASAP probe. All UV-Vis absorption spectra were recorded on a Hewlett Packard HP 8453 Diode array UV-visible spectrophotometer. Thin films were spin-coated from $o$-dichlorobenzene $(o$-DCB) at a spin speed of $2000 \mathrm{rpm}$ for $1 \mathrm{~min}$ onto cleaned glass slides. Fluorescence spectra were recorded using a Perkin-Elmer LS50B fluorimeter. PESA measurements were recorded using a Riken Keiki AC-2 PESA spectrometer with a power setting of $5 \mathrm{nW}$ and a power number of 0.5 . Samples for PESA were prepared on clean glass substrates.

Device fabrication and characterization of photovoltaic devices, and experimental details for the preparation of thin-film transistors have been reported previously. ${ }^{[37,38]}$

Crystals suitable for single-crystal X-ray diffraction were obtained by layering a $\mathrm{CH}_{2} \mathrm{Cl}_{2}$ solution of the complex with hexane. X-ray diffraction data were collected on a D8 Bruker diffractometer with an APEX2 area detector using graphite monochromated Mo-K $\alpha$ radiation $(\lambda=0.71073 \AA)$ from a $1 \mu \mathrm{S}$ microsource. Geometric and intensity data were collected using SMART software. ${ }^{[45]}$ The data were processed using SAINT ${ }^{[46]}$ and corrections for absorption were applied using SADABS ${ }^{[47]}$ The structures were solved using direct methods and refined with full-matrix least-squares methods on $F^{2}$ using the SHELX-TL package. ${ }^{[48]}$ Selected crystal data and details of data collection and structure refinement are listed in Table S1. In the structure of $\mathbf{N 5}$, the $\mathrm{CH}_{2} \mathrm{Cl}_{2}$ molecule of crystallisation was disordered over two positions $(0.59145)$ and the displacement ellipsoids and C-Cl bond lengths were restrained to be equal.

\section{5,5'-(5,5-dioctyl-5H-dibenzo[b, $d]$ silole-3,7-diyl)bis(thiophene-2-}

carbaldehyde): To a solution of 2-bromo-5-formylthiophene $(0.36 \mathrm{~g}$, $1.90 \mathrm{mmol})$ in 1,2-dimethoxyethane $(25.0 \mathrm{~mL})$ and $1 \mathrm{M}$ sodium carbonate $\left(\mathrm{Na}_{2} \mathrm{CO}_{3}\right) \quad(25.0 \mathrm{~mL})$ was added 9,9-dioctyl-9H-9silafluorene-2,7-bis(boronic acid pinacol ester) $(0.41 \mathrm{~g}, 0.61 \mathrm{mmol})$. The mixture was then degassed for 30 min by purging with $\mathrm{N}_{2}$ before tetrakis(triphenylphosphine)palladium $(0) \quad\left[\mathrm{Pd}\left(\mathrm{PPh}_{3}\right)_{4}\right] \quad(55 \mathrm{mg}$, $0.05 \mathrm{mmol}$ ) was added, and the reaction mixture was set to reflux for 4 hours. Upon the consumption of substrates (TLC, $1 \% \mathrm{MeOH} / \mathrm{CHCl}_{3}$ ) the yellow solution was allowed to cool to room temperature and water $(100 \mathrm{~mL})$ was added. The mixture was then extracted with $\mathrm{CHCl}_{3}(3 \times$ $30 \mathrm{~mL}$ ) and the combined organic layers were washed with $\mathrm{H}_{2} \mathrm{O}$, followed by brine, dried over $\mathrm{MgSO}_{4}$, filtered through a thin pad of $\mathrm{MgSO}_{4} / \mathrm{SiO}_{2}$ and evaporated to yield an oily, yellow residue. The crude 
product was then crystallized from $\mathrm{CH}_{2} \mathrm{Cl}_{2} / i$-PrOH to yield $1(0.28 \mathrm{~g}$, $73 \%)$ as fine yellow crystals. M. Pt. $=100-101{ }^{\circ} \mathrm{C} ;{ }^{1} \mathrm{H}$ NMR (300 MHz, $\left.\mathrm{CDCl}_{3}, \mathrm{ppm}\right): \delta=0.84\left(6 \mathrm{H}, \mathrm{t}, J=13.6,6.8 \mathrm{~Hz}, 2 \times \mathrm{CH}_{3}\right)$, $1.03\left(4 \mathrm{H}, \mathrm{m}, 2 \times \mathrm{CH}_{2}\right), 1.30\left(24 \mathrm{H}, \mathrm{m}, 2 \times \mathrm{Si}-\left(\mathrm{CH}_{2}\right)^{6}\right), 7.48(2 \mathrm{H}, \mathrm{d}, J=$ $4.0 \mathrm{~Hz}, \mathrm{ArH}), 7.78(4 \mathrm{H}, \mathrm{m}, \mathrm{ArH}), 7.90(4 \mathrm{H}, \mathrm{m}, \mathrm{ArH}), 9.92(2 \mathrm{H}, \mathrm{s}, 2 \times$ $\mathrm{CHO}) ;{ }^{13} \mathrm{C}$ NMR $\left(75 \mathrm{MHz}, \mathrm{CDCl}_{3}, \mathrm{ppm}\right): \delta=12.1,14.0,22.6,24.0$, 29.0, 29.2, 31.8, 33.2, 121.8, 124.0, 128.4, 131.1, 132.2, 137.4, 139.6, 142.3, 148.6, 154.3, 182.7 ; IR (neat, $\mathrm{cm}^{-1}$ ): $\widetilde{v}=2922$ (w), 2851 (w), 1662 (s), 1468 (w), 1433 (w), 1402 (w), 1378 (w), 1224 (m), 1057 (w), 1224 (m), 798 (s); HRMS (FTMS-ASAP) calculated for $\mathrm{C}_{38} \mathrm{H}_{46} \mathrm{O}_{2} \mathrm{~S}_{2} \mathrm{Si}$ $[\mathrm{M}]^{+}:$626.2703; found: $626.2704 \mathrm{~m} / \mathrm{z}$.

2,2'-(((5,5-dioctyl-5H-dibenzo[b,d] silole-3,7-diyl)bis(thiophene-5,2diyl))bis(methanylylidene))bis(1H-indene-1,3(2H)-dione) (N5): To a solution of 5,5'-(5,5-dioctyl-5H-dibenzo[ $b, d]$ silole-3,7diyl)bis(thiophene-2-carbaldehyde) $(0.256 \mathrm{~g}, 0.41 \mathrm{mmol})$ in $t$-BuOH $(50.0 \mathrm{~mL})$ was added 1,3 -indandione $(0.176 \mathrm{~g}, 1.21 \mathrm{mmol})$ followed by the addition of $1 \mathrm{~mL}$ of piperidine. The reaction mixture was refluxed for 6 hours under the stream of $\mathrm{N}_{2}$. The dark red solution was then cooled to $50{ }^{\circ} \mathrm{C}$ before ethanol $(50.0 \mathrm{~mL})$ was added and the flask was placed in the refrigerator overnight. The crude product was filtered off, washed with ethanol and crystallized from a hot solution of $\mathrm{CH}_{2} \mathrm{Cl}_{2} / i$ PrOH to afford N5 $(0.254 \mathrm{~g}, 72 \%)$ as fine, dark red to purple crystals. M.Pt. $=200-201{ }^{\circ} \mathrm{C} ;{ }^{1} \mathrm{H}$ NMR $\left(300 \mathrm{MHz}, \mathrm{CDCl}_{3}, \mathrm{ppm}\right): \delta=0.82(6 \mathrm{H}$, $\left.\mathrm{t}, J=13.6,6.4 \mathrm{~Hz}, 2 \times \mathrm{CH}_{3}\right), 1.09\left(4 \mathrm{H}, \mathrm{m}, 2 \times \mathrm{CH}_{2}\right), 1.30(24 \mathrm{H}, \mathrm{m}, \mathrm{Si}-$ $\left.\left(\mathrm{CH}_{2}\right)^{6}\right), 7.56(2 \mathrm{H}, \mathrm{d}, J=4.2 \mathrm{~Hz}, \mathrm{ArH}), 7.81(4 \mathrm{H}, \mathrm{m}, \mathrm{ArH}), 7.91(4 \mathrm{H}, \mathrm{m}$, $\mathrm{ArH}), 8.01(7 \mathrm{H}, \mathrm{m}, \mathrm{ArH}), 8.05(2 \mathrm{H}, \mathrm{m}, 2 \times$ methylidene- $\mathrm{CH}) ;{ }^{13} \mathrm{C}$ NMR (75 MHz, $\left.\mathrm{CDCl}_{3}, \mathrm{ppm}\right): \delta=12.2,14.0,22.6,25.3,29.1,29.2$, $31.8,33.3,121.8,122.7,123.0,124.7,128.5,131.1,132.4,134.8$, 135.0, 136.1, 136.6, 139.6, 140.5, 142.0, 143.6, 148.8, 157.3, 189.7, 190.2 ; IR (neat, $\mathrm{cm}^{-1}$ ): $\widetilde{v}=2920$ (w), 2851 (w) 1720 (w), 1676 (s), 1598 (m), 1580 (s), 1564 (s), 1432 (s), 1400 (m), 1372 (w), 1331 (w), 1205 (s), $992(\mathrm{~m}), 801$ (s), 728 (s); HRMS (FTMS-ASAP) calculated for $\mathrm{C}_{56} \mathrm{H}_{54} \mathrm{O}_{4} \mathrm{~S}_{2} \mathrm{Si}[\mathrm{M}]^{+}$: 882.3227; found: $882.3223 \mathrm{~m} / \mathrm{z}$.

\section{Acknowledgements}

S.V.B. (RMIT) acknowledges financial support from the Australian Research Council (ARC), Australia, under a Future Fellowship Scheme (FT110100152). The CSIRO Division of Materials Science and Engineering, Clayton, Victoria is acknowledged for providing support through a visiting fellow position (A.G.). P.S. is thankful to the ARC Future Fellowship Scheme (FT130101337) at Queensland University of Technology, Brisbane, Queensland.

Keywords: Dibenzosilole $\cdot$ 1,3-Indanedione $\cdot$ Bulk-heterojunction devices $\bullet$ Solution processing $\bullet$ Non-fullerene acceptor

[1] C. J. Brabec, S. Gowrisanker, J. J. M. Halls, D. Laird, S. Jia, S. P. Williams, Adv. Mater. 2010, 22, 3839-3856.

[2] Y. Lin, Y. Li, X. Zhan, Chem. Soc. Rev. 2012, 41, 4089-4380

[3] A. Mishra, P. Baüerle, Angew. Chem. Int. Ed. 2012, 51, 2020-2067.

[4] A. Facchetti, Chem. Mater. 2011, 23, 733-758

[5] L. Bian, E. Zhu, J. Tang, W. Tang, F. Zhang, Prog. Polym. Sci. 2012, 37, 1292-1331

[6] H. Zhou, L. Yang, W. You, Macromolecules 2012, 45, 607-632.

[7] J. B. You, L. T. Dou, K. Yoshimura, T. Kato, K. Ohya, T. Moriarty, K. Emery, C. C. Chen, J. Gao, G. Li, Y. Yang, Nat. Commun. 2013, 4, 1446-1455.

[8] J. T. Bloking, X. Han, A. T. Higgs, J. P. Kastrop, L. Pandey, J. E. Norton, C. Risko, C. E. Chen, J.-L. Brèdas, M. D. McGehee, A. Sellinger, Chem. Mater 2011, 23, 5484-5490
[9] Y. Lin, Y. Li, X. Zhan, Adv. Energy Mater. 2013, 3, 724-728

[10] H. Patil, A. Gupta, A. Bilic, S. V. Bhosale, S. V. Bhosale, Tetrahedron Lett. 2014, 55, 4430-4432

[11] Y. Lin, Y. Wang, J. Wang, J. Hou, Y. Li, D. Zhu, X. Zhan, Adv. Mater. 2014, $26,5137-5142$

[12] P. Cheng, L. Ye, X. Zhao, J. Hou, Y. Li, X. Zhan, Energy Environ. Sci. 2014, 7, 1351-1356

[13] H. Patil, W. X. Zu, A. Gupta, V. Chellappan, A. Bilic, P. Sonar, A. Rananaware, S. V. Bhosale, S. V. Bhosale, Phy. Chem. Chem. Phy. 2014, 16, 23837-23842

[14] A. M. Raynor, A. Gupta, H. Patil, A. Bilic, S. V. Bhosale, RSC Adv. 2014, 4, 57635-57638

[15] Y. Lin, P. Cheng, Y. Li, X. Zhan, Chem. Commun. 2012, 48, 4773-4775.

[16] X. Zhang, Z. Lu, L. Ye, C. Zhan, J. Hou, S. Zhang, B. Jiang, Y. Zhao, J. Huang, S. Zhang, Y. Liu, Q. Shi, Y. Liu, J. Yao, Adv. Mater. 2013, 25, 57915797.

[17] W. Chen, X. Yang, G. Long, X. Wan, Y. Chen, Q. Zhang, J. Mater. Chem. C 2015, 3, 4698-4705.

[18] W. Chen, T. Salim, H. Fan, L. James, Y. M. Lam, Q. Zhang, RSC Adv. 2014, 4, 25291-25301.

[19] Q. Zhang, J. Xiao, Z. Yin, H. M. Duong, F. Qiao, F. Boey, X. Hu, H. Zhang, F. Wudl, Chem. Asian J. 2011, 6, 856-862.

[20] Y. Lin, J. Wang, S. Dai, Y. Li, D. Zhu, X. Zhan, Adv. Energy Mater. 2014, 4, 1400420-425.

[21] H. Bai, Y. Wang, P. Cheng, J. Wang, Y. Wu, J. Hou, X. Zhan, J. Mater. Chem. A 2015, 3, 1910-1914.

[22] X. Zhan, Z. Tan, B. Domercq, Z. An, X. Zhang, S. Barlow, Y. Li, D. Zhu, B. Kippelen, S. R. Marder, J. Am. Chem. Soc. 2007, 129, 7246-7247

[23] S. Holliday, R. S. Ashraf, C. B. Nielsen, M. Kirkus, J. A. Röhr, C.-H. Tan, E. C.-Fregoso, A.-C. Knall, J. R. Durrant, J. Nelson, I. McCulloch, J. Am. Chem Soc. 2015, 137, 898-904.

[24] J. Zhao, Y. Li, H. Lin, Y. Liu, K. Jiang, C. Mu, T. Ma, J. Y. L. Lai, H. Hu, D Yu, H. Yan, Energy Environ. Sci. 2015, 8, 520-525

[25] Y. Lin, Z.-G. Zhang, H. Bai, J. Wang, Y. Yao, Y. Li, D. Zhu, X. Zhan, Energy Environ. Sci. 2015, 8, 610-616.

[26] Y. Lin, J. Wang, Z.-G. Zhang, H. Bai, Y. Li, D. Zhu, X. Zhan, Adv. Mater 2015, 27, 1170-1174.

[27] Y. He, Y. Li, Phys. Chem. Chem. Phys. 2011, 13, 1970-1983.

[28] R. Y. C. Shin, P. Sonar, P. S. Siew, Z. K. Chen, A. Sellinger, J. Org. Chem. 2009, 74, 3293-3298.

[29] P. Sonar, J. P. F. Lim, K. L. Chan, Energy Environ. Sci. 2011, 4, 1558-1574.

[30] Y. Lin, X. Zhan, Mater. Horiz. 2014, 1, 470-488.

[31] Y. Kim, C. E. Song, S.-J. Moon, E. Lim, Chem. Commun. 2014, 50, 8235 8237

[32] K. N. Winzenberg, P. Kemppinen, F. H. Scholes, G. E. Collis, Y. Shu, Th. B Singh, A. Bilic, C. M. Forsyth, S. E. Watkins, Chem. Commun. 2013, 49, 6307-6309.

[33] K. Tamao , M. Uchida , T. Izumizawa , K. Furukawa, S. Yamaguchi, J. Am. Chem. Soc. 1996 , 118, 11974-11975.

[34] K. L. Chan , M. J. McKiernan , C. R. Towns , A. B. Holmes, J. Am. Chem Soc. 2005, 27, 7662-7663.

[35 ] H. Usta , G. Lu , A. Facchetti , T. J. Marks , J. Am. Chem. Soc. 2006, 128 , 9034-9035.

[36 ] E. Wang, L. Wang, L. Lan, C. Luo, W. Zhuang, J. Peng, Y. Cao , Appl. Phys. Lett. 2008, $92,033307$.

[37] A. Gupta, A. Ali, A. Bilic, M. Gao, K. Hegedus, B. Singh, S. E. Watkins, G. J. Wilson, U. Bach, R. A. Evans, Chem. Commun. 2012, 48, 1889-1891.

[38] A. Gupta, V. Armel, W. Xiang, G. Fanchini, S. E. Watkins, D. R. MacFarlane, U. Bach, R. A. Evans, Tetrahedron 2013, 69, 3584-3592.

[39] R. J. Kumar, Q. I. Churches, J. Subbiah, A. Gupta, A. Ali, R. A. Evans, A. B Holmes, Chem. Commun. 2013, 49, 6552-6554.

[40] A. Gupta, A. Ali, T. B. Singh, A. Bilic, U. Bach, R. A. Evans, Tetrahedron 2012, 68, 9440-9447.

[41] Gaussian 09 (Revision D.01), M. J. Frisch, G. W. Trucks, H. B. Schlegel, G. E. Scuseria, M. A. Robb, J. R. Cheeseman, G. Scalmani, V. Barone, B. Mennucci, G. A. Petersson, H. Nakatsuji, M. Caricato, X. Li, H. P. Hratchian, A. F. Izmaylov, J. Bloino, G. Zheng, J. L. Sonnenberg, M. Hada, M. Ehara, K Toyota, R. Fukuda, J. Hasegawa, M. Ishida, T. Nakajima, Y. Honda, O. Kitao, H. Nakai, T. Vreven, J. A. Montgomery, Jr., J. E. Peralta, F. Ogliaro, M. 
Bearpark, J. J. Heyd, E. Brothers, K. N. Kudin, V. N. Staroverov, R Kobayashi, J. Normand, K. Raghavachari, A. Rendell, J. C. Burant, S. S Iyengar, J. Tomasi, M. Cossi, N. Rega, J. M. Millam, M. Klene, J. E. Knox, J. B. Cross, V. Bakken, C. Adamo, J. Jaramillo, R. Gomperts, R. E. Stratmann, O. Yazyev, A. J. Austin, R. Cammi, C. Pomelli, J. W. Ochterski, R. L. Martin, K. Morokuma, V. G. Zakrzewski, G. A. Voth, P. Salvador, J. J. Dannenberg, S Dapprich, A. D. Daniels, _. Farkas, J. B. Foresman, J. V. Ortiz, J. Cioslowski, D. J. Fox, Gaussian, Inc., Wallingford CT, 2013.

[42] J. H. Bannock, S. H. Krishnadasan, A. M. Nightingale, C. P. Yau, K. Khaw, D. Burkitt, J. J. M. Halls, M. Heeney, J. C. de Mello, Adv. Funct. Mater. 2013, 23 , 2123-2129.

[43] W. Xiang, A. Gupta, M. K. Kashif, N. Duffy, A. Bilic, R. A. Evans, L. Spiccia, U. Bach, CHEMSUSCHEM 2013, 6, 256-260

[44] G. Li, V. Shrotriya, J. Huang, Y. Yao, T. Moriarty, K. Emery, Y. Yang, Nat. Mater. 2005, 4, 864-868.

[45] SMART version 5.625 software for the CCD Detector System, Bruker AXS Inc., Madison, WI, 2001

[46] SAINTPLUS version 6.22 software for the CCD Detector System, Bruker AXS Inc., Madison, WI, 2001.

[47] SADABS program for absorption correction using SMART CCD data based on the method of Blessing: R. H. Blessing, Acta Crystallogr., Sect. A, 1995, $51,33$.

[48] G. M. Sheldrick, SHELXTL, version 6.10, University of Göttingen, Germany, 1994. 


\section{Entry for the Table of Contents}

\section{FULL PAPER}

A novel, solution-processable nonfullerene electron acceptor, N5 comprised of dibenzosilole and 1,3indanedione building blocks was designed, synthesized and fully characterized. Solution-processable bulk-heterojunction devices afforded promising power conversion efficiency $(2.76 \%)$ when N5 was used as a nonfullerene electron acceptor along with the conventional donor polymer poly(3-hexylthiophene).

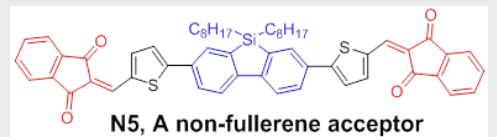

N5, A non-fullerene acceptor

ITO/P3HT:N5 (1:1)/Ca/AI PCE: $2.76 \%$
H. Patil, A. Gupta, B. Alford, D. Ma, S. H. Privér, A. Bilic, P. Sonar, S.V. Bhosale*

Page No. - Page No.

Conjoint use of dibenzosilole and indan-1,3-dione functionalities to prepare an efficient non-fullerene acceptor for solution-processable bulk-heterojunction devices 